DARLANE MARINHO DE SOUZA, TATIANA ISSIDA FUJINAMI, NADJA NARA DOURADO RODRIGUES SARTORIO, PRISCILA TOLEDO VIDAL LOPES, DANUBIA RIBEIRO DA SILVA

\title{
CUIDADO À SAÚDE DO HOMEM NA ATENÇÃO PRIMÁRIA DE SAÚDE
}

Eixo temático: Avaliação e Qualidade do Cuidado

INTRODUÇÃO: A Política Nacional de Atenção Integral à Saúde do Homem (PNAISH), instituída pela portaria GM/MS no 1944 de 27 de agosto 2009, vem contribuir para ampliação do acesso ao cuidado à saúde do homem, visando a redução da morbimortalidade nesta população. Estudos revelam que os homens procuram menos a Atenção Primária, comparados as mulheres, acessando o serviço de saúde já na atenção secundária e terciária de saúde, resultando em agravo da morbidade do indivíduo e gerando alto custo para o Sistema de Saúde. Entretanto, torna-se necessário reorganizar as ações nos serviços de saúde, ampliando o acesso para atendimento desta população na Atenção Primária de Saúde - APS. O trabalho tem por objetivo a reorganização e ampliação do acesso à saúde do homem, por meio do pré natal do parceiro na Unidade Básica de Saúde (UBS) Vila Izolina Mazzei.

METODOLOGIA: Trata-se de um relato de experiência das ações realizadas para reestruturação do acesso ao cuidado à saúde do homem, por meio do pré natal do parceiro na UBS Vila Izolina Mazzei. A amostra do trabalho é de abordagem quantitativa, consolidando os dados no período de 02 de Julho à 14 de Novembro 2018. Vale ressaltar, que não foram identificados registros de atendimento ao pré natal do parceiro precedente ao período analisado. A ação utilizou como ferramenta de gestão o instrumento $5 \mathrm{~W} 2 \mathrm{H}$, seguido do PDSA. A reorganização do processo fez uso da tecnologia leve-dura, por meio da vinculação do impresso de Pré Natal do parceiro ao prontuário da gestante além de desenvolver uma ficha de monitoramento e a elaboração de um folder em português e espanhol para sensibilização aos parceiros à acessar e vincular-se na APS.

RESULTADOS: O trabalho resultou em melhoria de acesso à saúde do homem na UBS Vila Izolina Mazzei, identificando 46 parceiros acolhidos - (ver figura 1) e atuantes aos serviços da APS, com a realização de 24 coleta de exames laboratoriais, 06 controle sinais vitais, 06 vacinação, 03 consultas clinicas e 04 odontológicas (ver gráfico1).

Figura 1 - Número de gestantes e parceiros acolhidos na UBS Vila Izolina Mazzei de julho à Novembro 2018.

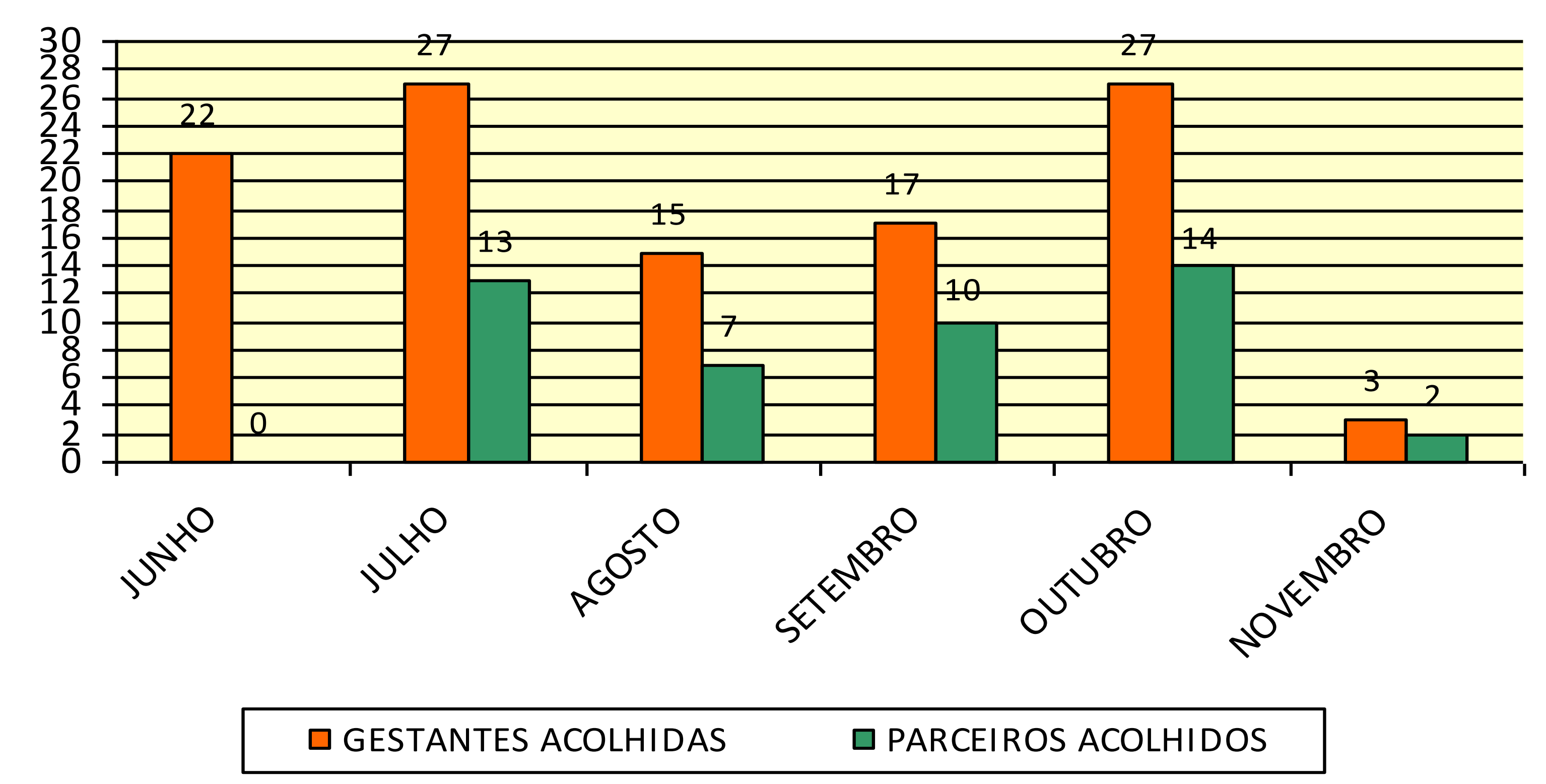

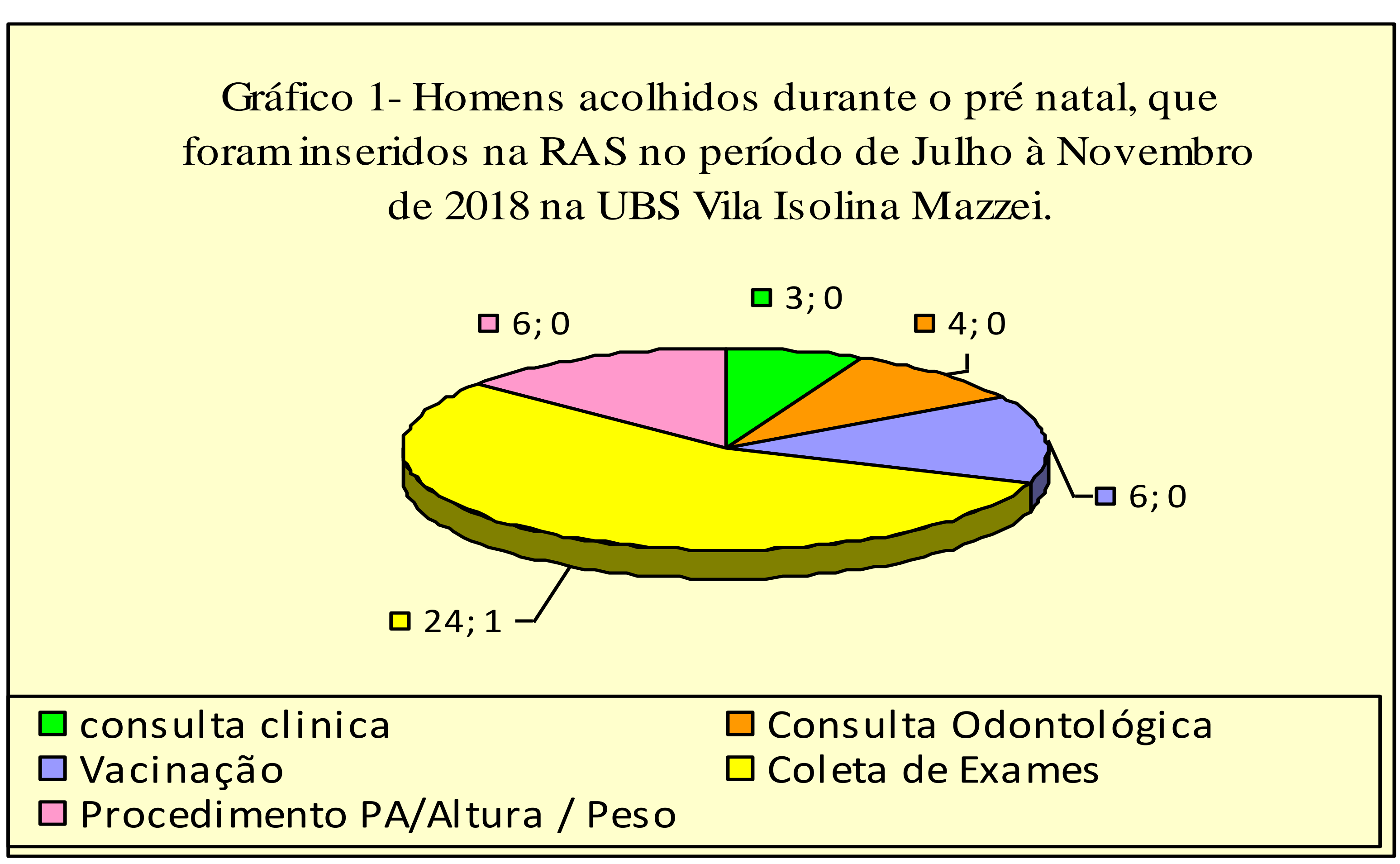

CONSIDERAÇÕES FINAIS: Os dados apresentados evidenciaram melhoria de acesso direcionado à saúde do homem por meio do Pré Natal do Parceiro acolhidos no período analisado, acessando os serviços de saúde na Atenção Primária de saúde, contribuindo para redução da morbimortalidade nesta população.

REFERÊNCIAS: . Herrmann, A. et.al. Guia do Pré-Natal do Parceiro para Profissionais de Saúde Ministério da Saúde, 55 p.: il - Rio de Janeiro 2016. 